\title{
Stress Corrosion Cracking Growth Rates of Candidate Canister Materials for Spent Nuclear Fuel Storage in Chloride-Containing Atmosphere
}

\author{
Jun-ichi Tani ${ }^{1}$, Masami Mayuzumi ${ }^{1,2}$, Taku Arai $^{1}$ and Nobuyoshi Hara ${ }^{3}$ \\ ${ }^{1}$ Central Research Institute of Electric Power Industry, Materials Science Research Laboratory, \\ Yokosuka 240-0196, Japan \\ ${ }^{2}$ Tokyo Institute of Technology, Graduate School of Science and Engineering, Department \\ of Mechanical Science and Engineering, Tokyo 152-8552, Japan \\ ${ }^{3}$ Tohoku University, Graduate School of Engineering, Department of Metallurgy, Sendai 980-8579, Japan
}

\begin{abstract}
Chloride-induced stress corrosion crack growth rates were measured for candidate canister materials in a simulated marine atmospheric environment. Half-inch compact tension specimens were used to obtain stress corrosion crack growth rates by applying a direct-current potential-drop method to measure crack lengths. The crack growth rates of S31603 and S31260 stainless steels were $3 \times 10^{-10} \mathrm{~m} \cdot \mathrm{s}^{-1}$ and $4 \times 10^{-13} \mathrm{~m} \cdot \mathrm{s}^{-1}$ for an applied stress intensity factor of $30 \mathrm{MPa} \cdot \mathrm{m}^{0.5}$, respectively, at a test temperature of $353 \mathrm{~K}$ at a relative humidity of $35 \%$. S31254 specimens did not show stress corrosion cracking susceptibility under the same conditions as above, suggesting their superior resistance to chloride-induced stress corrosion cracking. These data were consistent with the results that S31260 and S31254 stainless steels did not fail after up to $37700 \mathrm{~h}$ although S31603 failed after $533 \mathrm{~h}$ in constant-load tests under the same environmental conditions. Assuming active-path corrosion to be an anodic subprocess of stress corrosion crack growth, anodic polarization curves of the test materials were obtained in a synthetic seawater solution of $\mathrm{pH} 1$ at $353 \mathrm{~K}$. The maximum anodic current density of the active dissolution of S31603 stainless steel was ten times as large as that of S31260 stainless steel. This result qualitatively explains the difference in the crack growth behavior between S31603 and S31260 stainless steels. [doi:10.2320/matertrans.MRA2006367]
\end{abstract}

(Received December 28, 2006; Accepted March 12, 2007; Published May 25, 2007)

Keywords: concrete cask, stainless steel, canister, stress corrosion cracking, sea salt

\section{Introduction}

In the dry storage of spent nuclear fuels using concrete casks, stainless-steel canisters act as an important barrier to encapsulate spent fuels and radioactive materials. According to the storage concept, the decay heat of the spent fuels is removed through the canister wall by air cooling. Hence, the canister wall is in direct contact with air containing sea salt particles and might be contaminated by chlorides, since the facility will be located in a coastal area and the expected service life is a long period of 40 to 60 years.

Stainless steels are widely used as structural materials for chemical plants and nuclear power plants because of their superior general corrosion resistance, mechanical properties, and weldability. However, it is well known that austenitic stainless steels are susceptible to stress corrosion cracking (SCC) in certain environments under a tensile stress. SCC induced by sea salt particles and chlorides, for example, is observed on various components in chemical plants built in coastal areas. ${ }^{1)}$ This type of SCC is referred to as external SCC (ESCC) or atmospheric SCC since the cracking starts from the outside of the equipment in air.

ESCC manifests itself as intergranular cracking or transgranular cracking depending on the material condition and temperature. Intergranular SCC is usually observed in the sensitized parts of stainless-steel components at around ambient temperature. On the other hand, transgranular SCC is observed regardless of the material conditions at relatively high temperatures above $327 \mathrm{~K}$. As one environmental factor, a certain degree of relative humidity $(\mathrm{RH})$ is necessary to moisten the chlorides adhered to the stainless-steel surface. The relative humidity for which ESCC easily occurs (RHp) is dependent on the type of chloride. Shoji et al. reported, ${ }^{2)}$ for example, RHp values of $60 \%$ for $\mathrm{NaCl}$ and $30 \%$ for $\mathrm{MgCl}_{2}$, respectively. Another important factor of ESCC, tensile stress, is mostly derived from the residual stress resulting from welding or cold working.

The storage canister has several welding lines in the wall and lid, which probably have high residual tensile stresses. Contamination by sea salt particles also is expected to occur during the long service life of canisters, as mentioned previously. Thus, susceptibility to ESCC should be evaluated carefully for candidate canister materials.

Hence, the purpose of this study is to evaluate i) the ESCC susceptibility of two candidate materials, S31260 and S31254 stainless steels (SSs), and ii) environmental factors affecting the ESCC behavior of stainless steels. SCC tests at $333 \mathrm{~K}, 343 \mathrm{~K}$ and $353 \mathrm{~K}$ have already been reported. ${ }^{3,4)}$ Considering 40 to 60 years of storage, it is necessary to understand SCC behavior at lower temperature. One of our objectives in this report is to examine the SCC susceptibility of stainless steels at $323 \mathrm{~K}$. Additionally, the results of a longterm test at $353 \mathrm{~K}$ are also given. Another objective in this report is to explain the reason why S31260 and S31254 SSs did not fail over a long period of time in a constant-load test. For this purpose, the crack growth rate and anodic dissolution rate of the SSs were measured.

\section{Experiment}

\subsection{Materials}

50-mm-thick welded joints of S31260 SS and S31254 SS were prepared together with 2-mm-thick plates of S30403 SS and S31603 SS. Table 1 shows the chemical composition of the test materials. S30403, S31260, S31254(1) and S31603(1) were used for constant-load tests and electro- 
Table 1 Chemical composition of test materials.

\begin{tabular}{|c|c|c|c|c|c|c|c|c|c|c|c|}
\hline material & $\mathrm{C}$ & $\mathrm{Si}$ & $\mathrm{Mn}$ & $\mathrm{P}$ & S & $\mathrm{Cu}$ & $\mathrm{Ni}$ & $\mathrm{Cr}$ & Mo & $\mathrm{W}$ & $\mathrm{N}$ \\
\hline S31260 & 0.01 & 0.41 & 0.45 & 0.024 & 0.001 & 0.49 & 6.88 & 25.67 & 3.33 & 0.4 & 0.23 \\
\hline weld metal & 0.016 & 0.3 & 0.5 & 0.008 & 0.002 & 0.49 & 9.06 & 25.28 & 3.06 & 1.96 & 0.22 \\
\hline S31254(1) & 0.013 & 0.51 & 0.55 & 0.023 & 0.001 & 0.62 & 17.84 & 19.84 & 6.12 & & 0.19 \\
\hline weld metal & 0.02 & 0.13 & 0.11 & 0.009 & 0.001 & 0.14 & 55.88 & 21.59 & 8.34 & & \\
\hline $\mathrm{S} 31254(2)$ & 0.013 & 0.47 & 0.55 & 0.023 & 0.001 & & 17.75 & 19.7 & 6.14 & & \\
\hline S31603(2) & 0.018 & 0.6 & 0.81 & 0.028 & 0.001 & & 12.24 & 17.32 & 2.09 & & \\
\hline S30403 & 0.02 & 0.67 & 1.34 & 0.032 & 0.002 & & 9.69 & 18.13 & & & \\
\hline
\end{tabular}

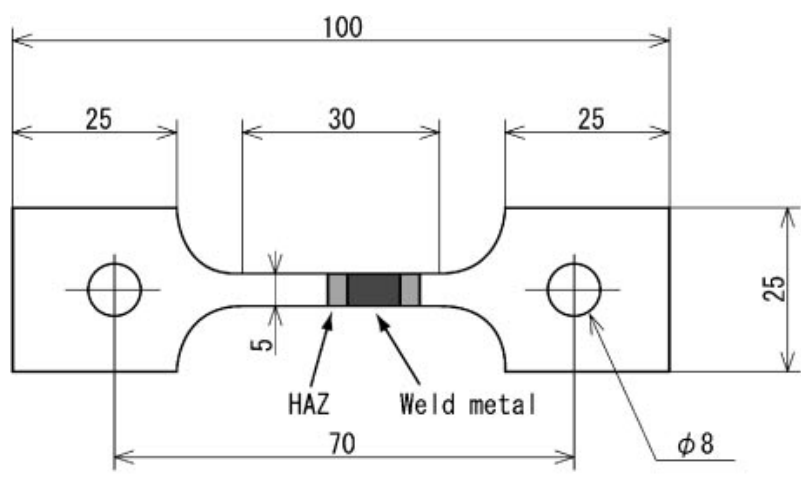

$$
\mathrm{t}=1.5 \text { or } 2.0 \mathrm{~mm}
$$

Fig. 1 Shape and dimensions of a specimen for constant-load test.

chemical measurements. S31260, S31254(2) and S31603(2) were used for crack growth measurements.

\subsection{Constant-load test}

Stress corrosion cracking tests were conducted by a constant-load method using a spring for loading. Figure 1 shows the shape and dimensions of a constant-load-test specimen. From the welded joints, tensile specimens with a gage section $1.5 \mathrm{~mm}$ (S31260) or $2 \mathrm{~mm}$ (S31254) thick, $5 \mathrm{~mm}$ wide, and $30 \mathrm{~mm}$ long were machined so as to contain the welded part in the gage section. Tensile specimens of the same shape ( $2 \mathrm{~mm}$ thick) also were cut from S30403. After machining, the specimens were polished using emery papers to \#600, degreased with acetone, rinsed with deionized water, and then attached to a loading apparatus that uses a spring to apply stress. Stress applied to the SS ranged from $0.25 \sigma_{0.2}$ to $1.75 \sigma_{0.2}$ (where $\sigma_{0.2}: 0.2 \%$ proof stress). To deposit chlorides simulating sea salt particles on the gage section of the specimen, droplets $(5 \times 10 \mu \mathrm{L})$ of synthetic sea water were placed on the gage section using a micropipette and dried. The major ingredients of synthetic sea water are sodium chloride, magnesium chloride and sodium sulfate. The resultant surface chlorine concentration was higher than $10 \mathrm{~g} \cdot \mathrm{m}^{-2}$ as $\mathrm{Cl}$ on the gage section. The loading apparatus containing a specimen was placed in a constant-temperatureand-humidity chamber at $323 \mathrm{~K}$ and $353 \mathrm{~K}$ with $\mathrm{RH}=35 \%$.

\subsection{Crack growth test}

Half-inch compact tension specimens were machined from test materials. Figure 2 shows the shape and dimensions of

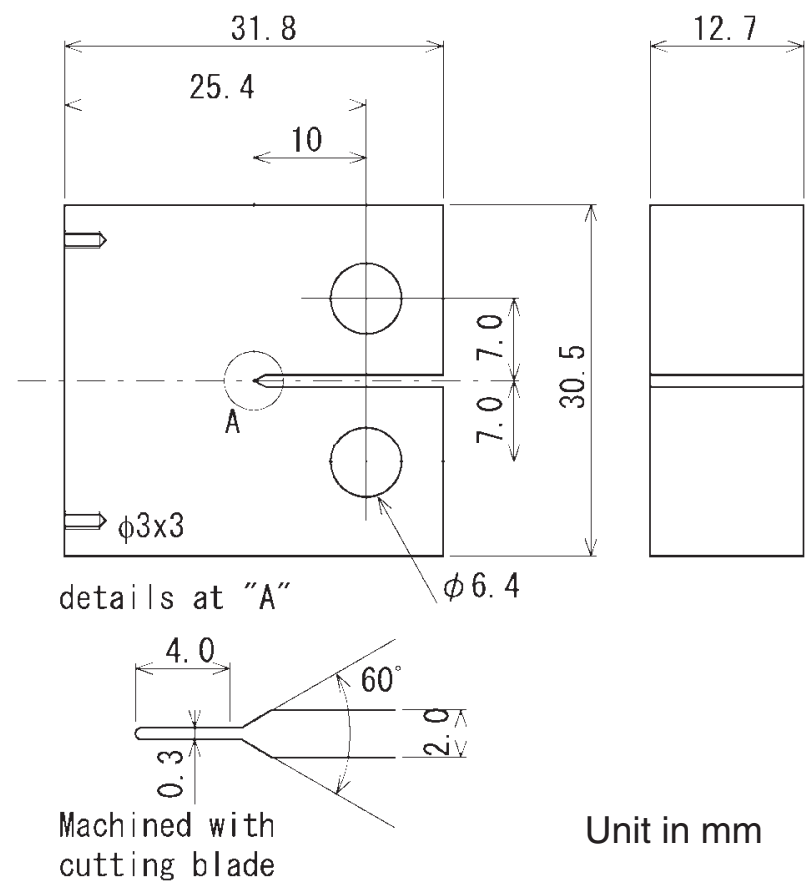

Fig. 2 Shape and dimensions of a specimen for crack growth measurement.

the compact tension specimen. The preliminary test showed that the use of a machined notch is suitable for initiating cracking rather than a fatigue pre-crack. After the specimen was set on the loading apparatus, $20 \mu \mathrm{L}$ of synthetic sea water was injected into the machined notch. The load was applied using a spring of $20 \mathrm{~cm}$ in length, to minimize the change in the stress intensity factor with crack growth. A load was applied to give a stress intensity factor of 5 to $30 \mathrm{MPa} \cdot \mathrm{m}^{0.5}$ on specimens, assuming the existence of a sharp precrack on the bottom of the machined notch. The crack length was measured by an alternating DC potential-drop method. The configuration of the potential-drop system is illustrated in Fig. 3. A current of $1.5 \mathrm{~A}$ was supplied to specimens during the potential measurement. The loading apparatus containing a specimen was placed in a chamber of constant humidity and temperature. The test temperatures were $323 \mathrm{~K}$ and $353 \mathrm{~K}$, and the relative humidity in the test was $35 \%$. One test was continued for at least 1000 hours. After the test, specimens were fractured by fatigue cycles, and the fractured surfaces were observed using a scanning electron microscope (SEM). The average crack length was measured using a microscope 
Constant humidity, constant temperature chamber

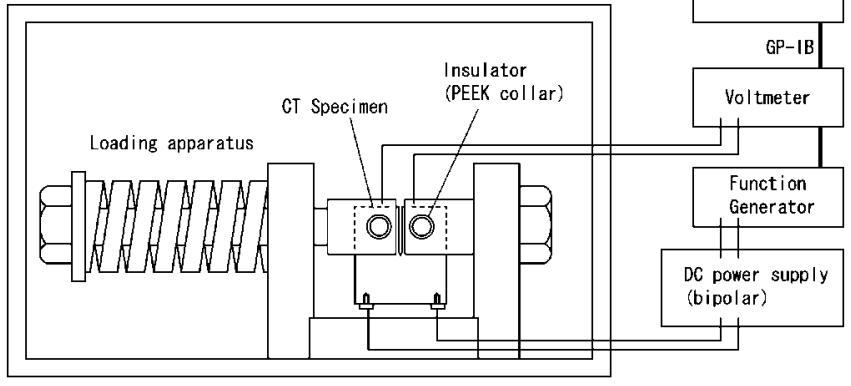

Fig. 3 DC potential-drop system and loading apparatus for crack growth test.

photograph, and then the crack growth rate was calculated from the potential-drop data and the crack length.

\subsection{Measurement of anodic dissolution rate}

Anodic polarization curves of the stainless steels in synthetic sea water were measured to discuss the results of the SCC test from the viewpoint of the anodic dissolution of the crack tip. A working electrode of $11 \times 11 \mathrm{~mm}$ was mounted in epoxy resin, then the electrode surface was polished using \#600 grit emery paper. Two kinds of synthetic seawater of $\mathrm{pH} 7$ and $\mathrm{pH} 1$ were used at $353 \mathrm{~K}$. The $\mathrm{pH}$ of the acidic solution was adjusted by adding a small amount of hydrochloric acid. The electrolyte solutions were deaerated by bubbling with pure nitrogen. The potential was swept from the open circuit potential in the anodic direction at a rate of $3.33 \times 10^{-4} \mathrm{~V} \cdot \mathrm{s}^{-1}$.

\section{Results}

\subsection{Constant-load test}

Figure 4 shows the surface morphology of S30403 specimens tested at $323 \mathrm{~K}$ with $\mathrm{RH}=35 \%$ for $14800 \mathrm{~h}$. Cracks were observed on the specimens with the applied stresses of $0.5 \sigma_{0.2}, 1.0 \sigma_{0.2}$ and $1.5 \sigma_{0.2}$, although all the specimens showed corrosion at the region where sea salt particles were deposited. Not even a small incipient crack was observed on the specimen loaded at $0.25 \sigma_{0.2}$. The specimens of S31260 and S31254 also showed corrosion on the gage section similar to that observed on the specimen of S30403 SS. However no crack was observed on the former specimens.

The relationship between the applied stress and the failure time is shown in Fig. 5 for the three types of SS tested at $323 \mathrm{~K}$ with $\mathrm{RH}=35 \%$. Two specimens of S30403 SS failed within $4000 \mathrm{~h}$ at an applied stress of above $350 \mathrm{MPa}$. S31260 SS and S31254 SS did not fail until $14800 \mathrm{~h}$, even though the applied stress was larger than $350 \mathrm{MPa}$.

Figure 6 shows the relationship between the applied stress and the failure time for various SSs at $353 \mathrm{~K}$ with $\mathrm{RH}=35 \%$. S31260 SS and S31254 SS did not fail for $37700 \mathrm{~h}$, while $\mathrm{S} 30403 \mathrm{SS}^{3,4)}$ and $\mathrm{S} 31603 \mathrm{SS}^{5)}$ failed at $250 \mathrm{~h}$ and $533 \mathrm{~h}$, respectively, under the same test conditions.

Specimens of S31260 SS and S31254 SS have weld metal and heat-affected zone on the gage section. By observing on the surfaces of the specimens tested after $15000 \mathrm{~h}$ with SEM, no obvious difference in corrosion properties among the weld metal, the heat-affected zone and the base metal was found.

\subsection{Crack growth rate}

Figure 7 shows the side view and the fracture surface of a S31603 SS compact tension (CT) specimen tested at $353 \mathrm{~K}$ with $\mathrm{RH}=35 \%$. From the side view (Fig. 7(a)), it is clearly seen that SCC is initiated at the bottom of the machined notch. This appearance is similar to that observed for SCC initiation in an aqueous environment. ${ }^{6)}$ In the fracture surface of the CT specimen, SCC is initiated relatively homogeneously along the machined notch. This behavior is the same as at observed in aqueous environment. ${ }^{6}$ Thus, a CT specimen was found to be useful for measuring stress corrosion crack growth rates in the atmosphere.

Figure 8 shows the change in the crack length of a S31603 SS CT specimen with elapsed time at $353 \mathrm{~K}$ and $\mathrm{RH}=35 \%$. The crack length was evaluated from the potential-drop data, and the average crack length was measured on the fracture surface. Although the crack tip was covered with sea salt particles or rust, the potential-drop system functioned very well at measuring the crack length of the CT specimen. SCC propagated shortly after the start of the test without an incubation time. The crack growth rate was obtained from the region where the crack length increased in proportion to the elapsed time, as shown in Fig. 8. Figure 9 shows the relationship between the crack growth rate, da/dt, of S31603 SS and the stress intensity factor, K. Under the conditions of $353 \mathrm{~K}$ and $\mathrm{RH}=35 \%$, large crack growth rates of around $3 \times 10^{-10} \mathrm{~m} \cdot \mathrm{s}^{-1}$ were obtained for $\mathrm{K}$ values larger than $10 \mathrm{MPa} \cdot \mathrm{m}^{0.5}$, and no clear dependence of the crack growth rate on $\mathrm{K}$ was observed. The crack growth rate at $323 \mathrm{~K}$ was about 400 times as small as that of obtained at $353 \mathrm{~K}$ in the same $\mathrm{K}$ region.

Figure 10 shows the change in the crack length of a S31260 SS CT specimen with elapsed time at 353 K. S31620 SS showed almost no crack growth under the condition of $\mathrm{RH}=35 \%$. When RH was increased to $75 \%$, SCC propagated and the resultant crack growth rate was $1.66 \times$ $10^{-11} \mathrm{~m} \cdot \mathrm{s}^{-1}$. In our past experience, we found that $\mathrm{RH}=$ $35 \%$ was the most suitable condition for the initiation of SCC in stainless steel and that the presence of $\mathrm{MgCl}_{2}$ is responsible for SCC. Since $\mathrm{NaCl}$, the major ingredient of the synthetic sea water, deliquesces at $\mathrm{RH}=75 \%$, it is suggested that $\mathrm{NaCl}$ plays an important role in the SCC process for S31260 SS at $353 \mathrm{~K}$. Figure 11 shows the fracture surface of the S31260 SS CT specimen having two types of corroded region, typical transgranular cracking and pitting corrosion. Figure 12 shows the relationship between the crack growth rate of S31260 SS and the applied stress intensity factor at $353 \mathrm{~K}$. The crack growth rate at $\mathrm{RH}=75 \%$ is larger than that at $\mathrm{RH}=35 \%$. Note that the measured values of the crack growth rate reflect merely an increase in electrical resistance, namely, a decrease in the cross-sectional area, and hence we could not separate the contributions from pitting and SCC extension in Fig. 12.

Crack growth measurement for S31254 was also conducted in the same manner as the test for S31260. No change was observed for the potential drop signal of test at $353 \mathrm{~K}$, relative humidity of both $35 \%$ and $75 \%$ and $\mathrm{K}=30$ $\mathrm{MPa} \cdot \mathrm{m}^{0.5}$. A small corroded area was observed on the fractured surface of this specimen, although the morphology could not be specified as that of cracking. 

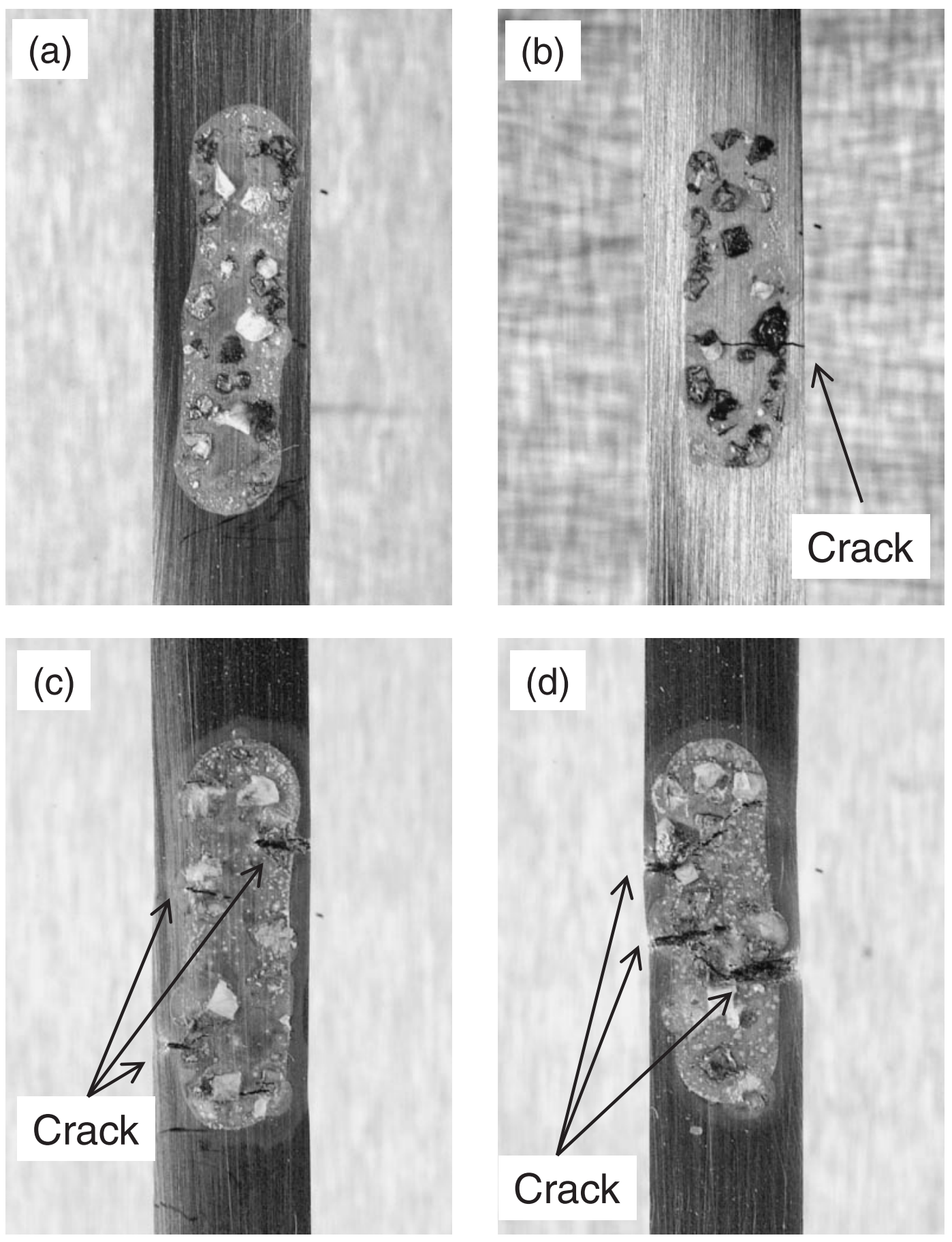

Fig. 4 Photographs of constant-load specimens of S30403 tested at $323 \mathrm{~K}$ and $\mathrm{RH}=35 \%$ for $14800 \mathrm{~h}$. The applied stresses were (a) $0.25 \sigma_{0.2}$, (b) $0.5 \sigma_{0.2}$, (c) $1.0 \sigma_{0.2}$, (d) $1.5 \sigma_{0.2}$.

\subsection{Anodic dissolution rate}

If we assume that the process of active-path corrosion is associated with SCC induced by sea salt particles, then the anodic dissolution rate is one measure of the susceptibility to this type of SCC. Hence, anodic polarization curves were obtained for the test materials in synthetic seawater. The solution $\mathrm{pH}$ was adjusted to $\mathrm{pH} 1$ adding $\mathrm{HCl}$ under the assumption that chloride ions condensate at the SCC tip and at a lower $\mathrm{pH}$ through the hydrolysis of cations. Figure 13 shows the anodic polarization curves of S30403 SS, S31603 SS, S31260 SS, and S31254 SS obtained at $353 \mathrm{~K}$ in (a) neutral synthetic seawater and (b) synthetic seawater of $\mathrm{pH} 1$. The active dissolution current peaks were clear in the test solution with $\mathrm{pH} 1$ for all the SS specimens. The peaks for S31260 SS and S31254 SS are small compared with those for S30403 SS and S31603 SS and are only 2 to 3 times larger than the passive current density. Table 2 summarizes the anodic dissolution peak current densities in both the test solutions. The peak current densities for S31260 SS and S31254 SS were $1 / 250$ and $1 / 750$ of that for S30403 SS, respectively. 


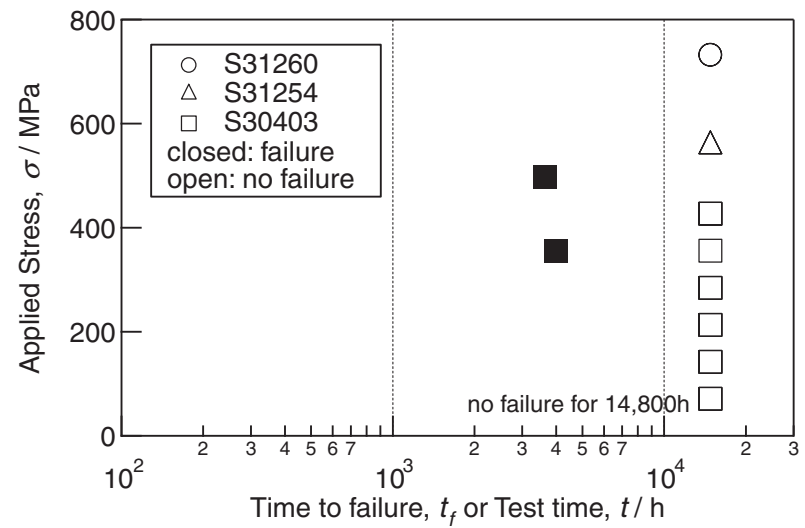

Fig. 5 Results of constant-load test at $323 \mathrm{~K}$ with $\mathrm{RH}=35 \%$.

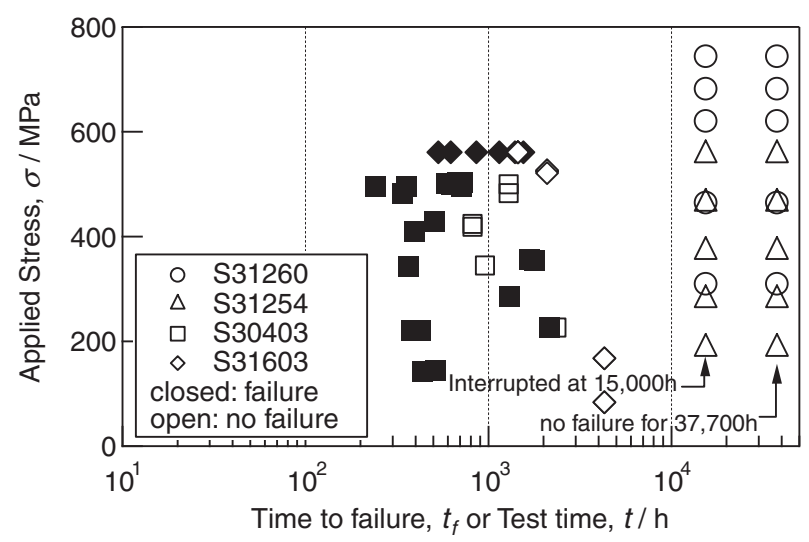

Fig. 6 Results of constant-load test at $353 \mathrm{~K}$ with $\mathrm{RH}=35 \%$.

\section{Discussion}

Generally, the stress corrosion crack growth rate of stainless steel or nickel-based alloys does not change significantly with time during tests in high-temperature water. ${ }^{6,7)}$ In this study, however, it decreased with time, as shown in Fig. 8. Since the crack-opening displacement was too small to relax the applied load of a spring, the decrease in the crack growth rate observed in Fig. 8 should be attributed to another factor. In spite of such an unsolved problem, the result of the present study strongly implies the necessity of continuous crack growth monitoring during a stress corrosion crack growth test under atmospheric conditions. We demonstrated that the potential-drop method is useful for measuring stress corrosion crack growth rates in a corrosive environment. Neither salt solution nor rust inside the machined notch interfered with the crack length measurement by potentialdrop method.

Itoh et al. ${ }^{8)}$ examined the small incipient cracks on uniaxial tensile SCC specimens, which were the same as those used in our previous study, ${ }^{3,4)}$ and calculated the crack growth rate by assuming no incubation time. The resultant stress corrosion crack growth rates were $1.6 \times 10^{-12} \mathrm{~m} \cdot \mathrm{s}^{-1}$ and $1.1 \times 10^{-12}$ $\mathrm{m} \cdot \mathrm{s}^{-1}$ for S31260 SS and S31254 SS, respectively. The stress corrosion crack growth rate of S31260 SS was larger than that obtained in this study under the same test environment
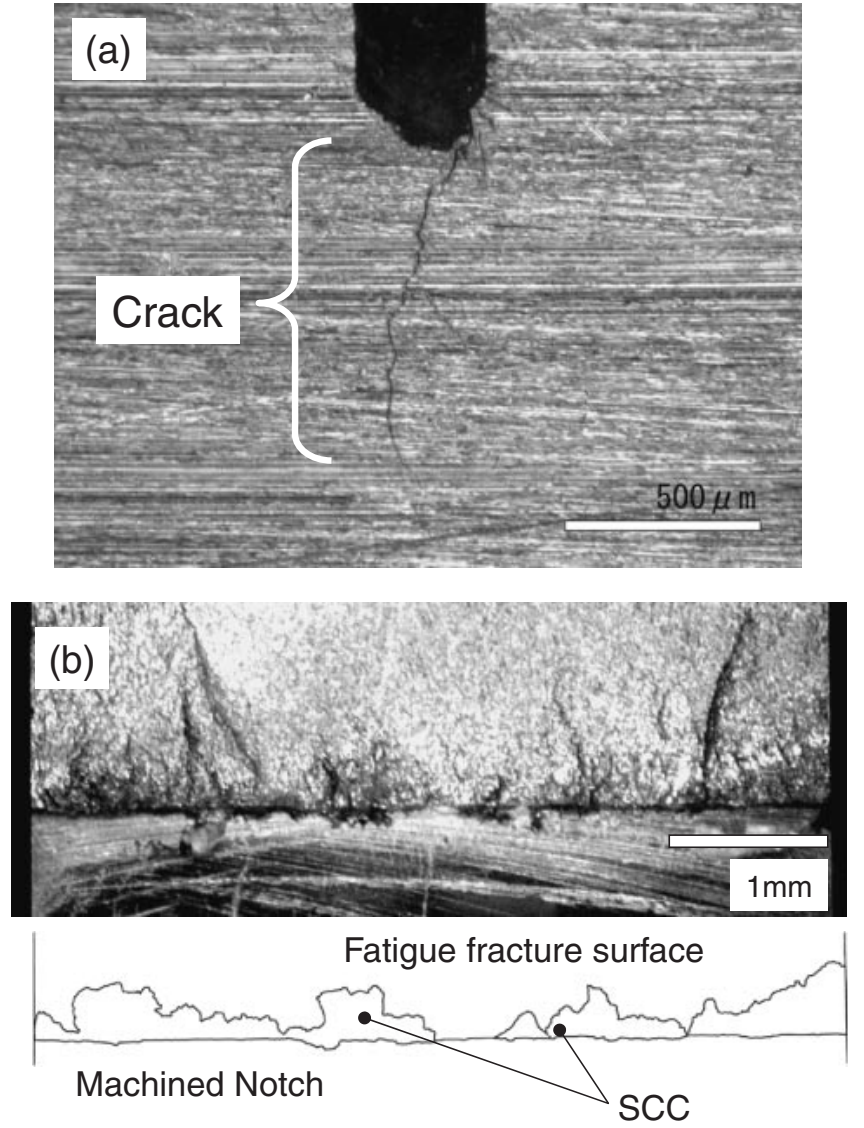

Fig. 7 Photographs of a CT specimen of S31603 tested at $353 \mathrm{~K}$ with $\mathrm{RH}=35 \%$. (a) Side view at the tip of machined notch, (b) SCC fracture surface.

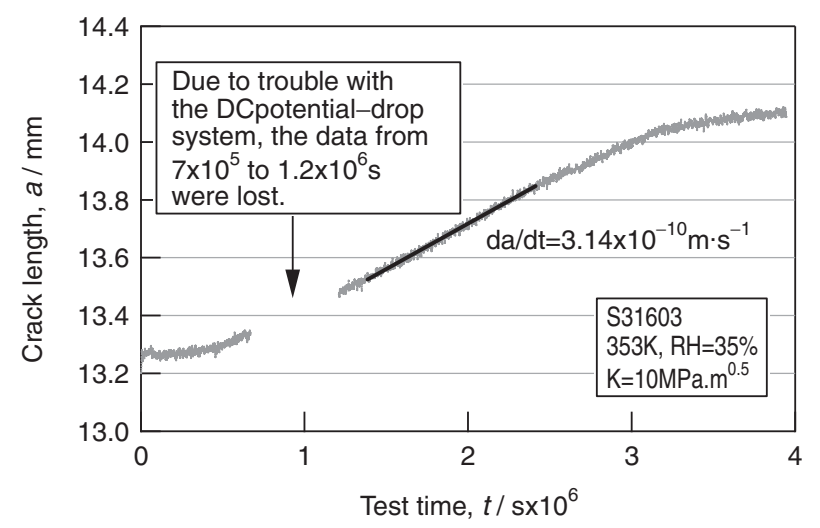

Fig. 8 Change in crack length with time for S31603 CT specimen tested at $353 \mathrm{~K}$ with $\mathrm{RH}=35 \%$.

$(\mathrm{RH}=35 \%, 353 \mathrm{~K})$. This difference is caused by the calculation method of stress corrosion crack growth rates.

Stress corrosion cracking is usually evaluated during the initial stage and propagation stage separately. For initiation of the SCC, we observed cracking on constant-load specimens in a short test time. For S30403 SS, cracks were observed in $3 \mathrm{~h}$ or $5 \mathrm{~h}$ at $353 \mathrm{~K}$ with $\mathrm{RH}=35 \%$. $^{5)}$ Although the candidate canister materials, S31260 SS and S31254 SS, did not fail during the long test period of $37700 \mathrm{~h}$, some rust spots were observed on the specimen surface. To observe the 


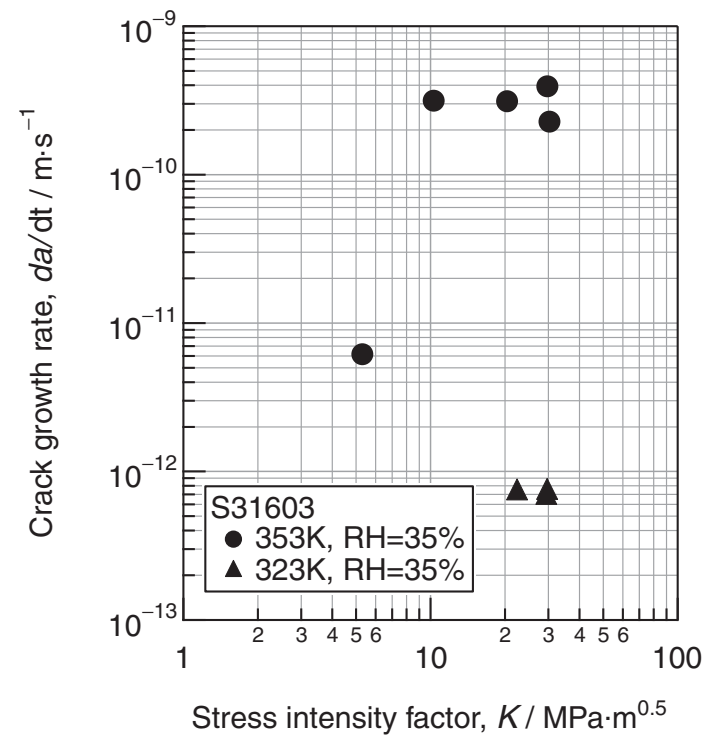

Fig. 9 Relationship between the crack growth rate and the stress intensity factor for S31603.

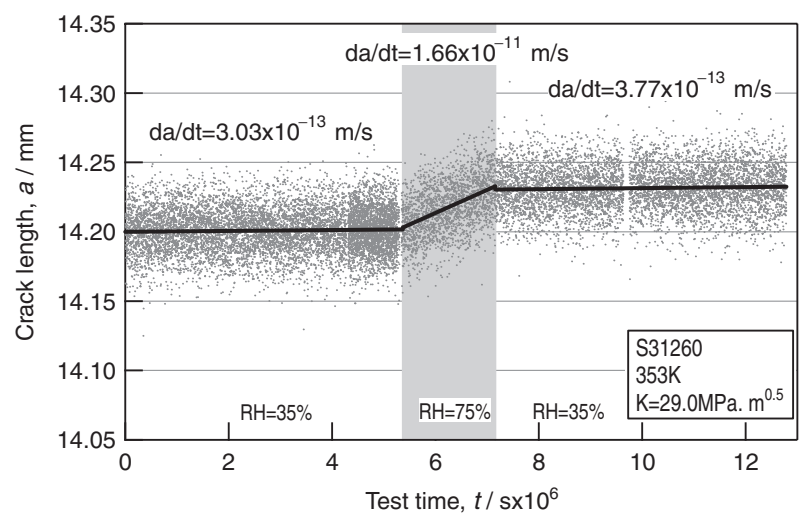

Fig. 10 Change in crack length with time for S31260 CT specimen tested at $353 \mathrm{~K}$. Relative humidity was initially set to $35 \%$, then increased to $75 \%$, and finally decreased again to $35 \%$ during the test.

initial state of corrosion on the specimen surface, some of the tests at $353 \mathrm{~K}$ with $\mathrm{RH}=35 \%$ for S31260 SS and S31254 SS specimens were interrupted after $1000 \mathrm{~h}$. Small incipient cracks were observed even after $27 \mathrm{~h}$, suggesting that the incubation time is very short, less than $100 \mathrm{~h}$ in this case. ${ }^{9)}$ Because cracks initiate in a short time for every kind of stainless steel that we used for this study, it is suggested that the high SCC resistances of S31260 SS and S31254 SS are attributable to their high resistances to stress corrosion crack growth.

Pitted areas are assumed to be the initiation sites of cracking. We previously measured the temperature dependence of the pitting potential for the materials used in this report. ${ }^{3,5)}$ About $1 \mathrm{~V}$ vs. SCE of pitting potential was obtained for S31260 SS and S31254 SS at $323 \mathrm{~K}$ while $0 \mathrm{~V}$ vs. SCE was obtained for S30403 SS. These values of S31260 SS and S31254 SS are almost equal to the potential for oxygen or chlorine evolution. At $353 \mathrm{~K}$, the pitting potential is $-0.1 \mathrm{~V}$ vs. SCE for S30403 SS, $0.1 \mathrm{~V}$ vs. SCE for S31260 SS, and about $0.5 \mathrm{~V}$ vs. SCE for S31254 SS. These results explain
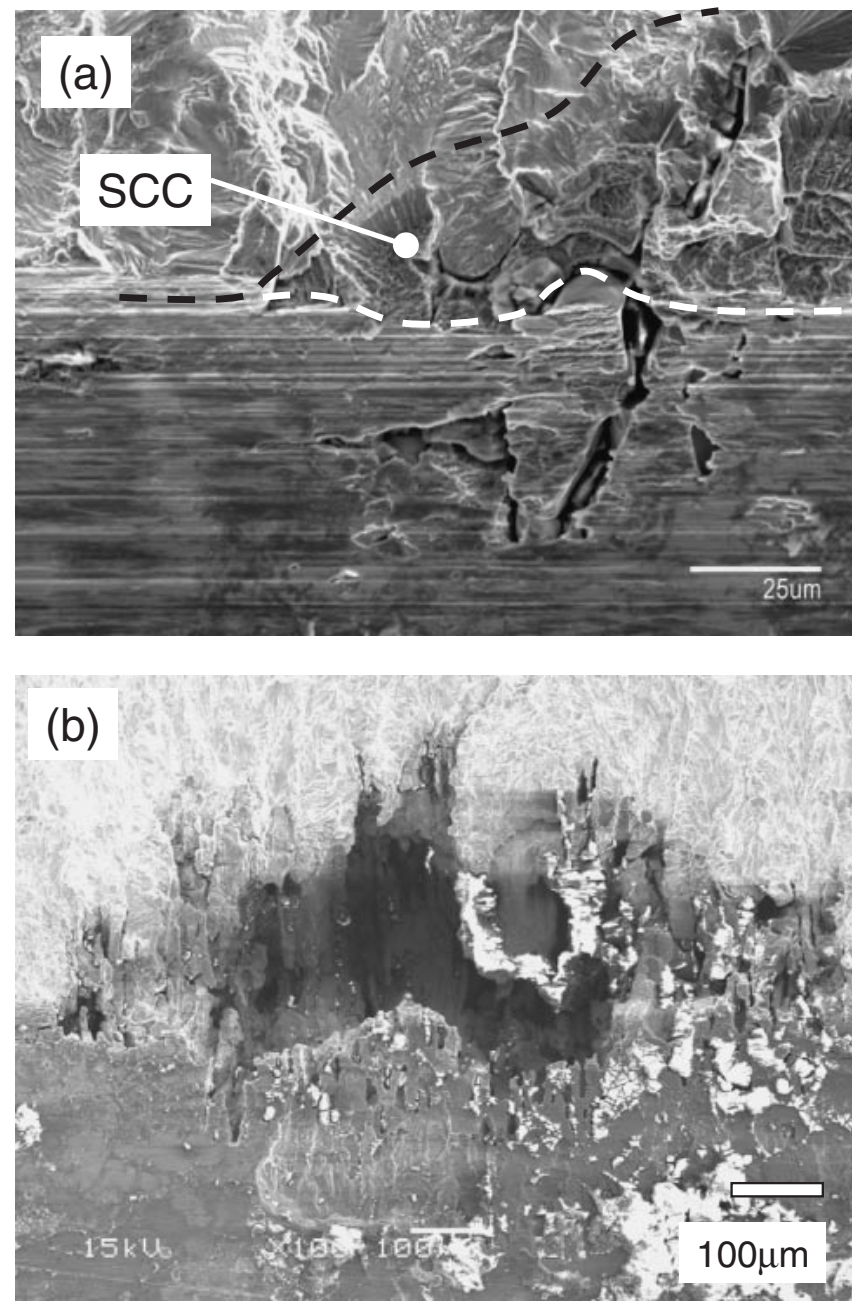

Fig. 11 Photographs of fractured surface of S31260 specimen after crack growth test at $353 \mathrm{~K}$. Relative humidity was initially set to $35 \%$, then increased to $75 \%$, and finally decreased again to $35 \%$ during the test, (a) stress corrosion crack, (b) pitting.

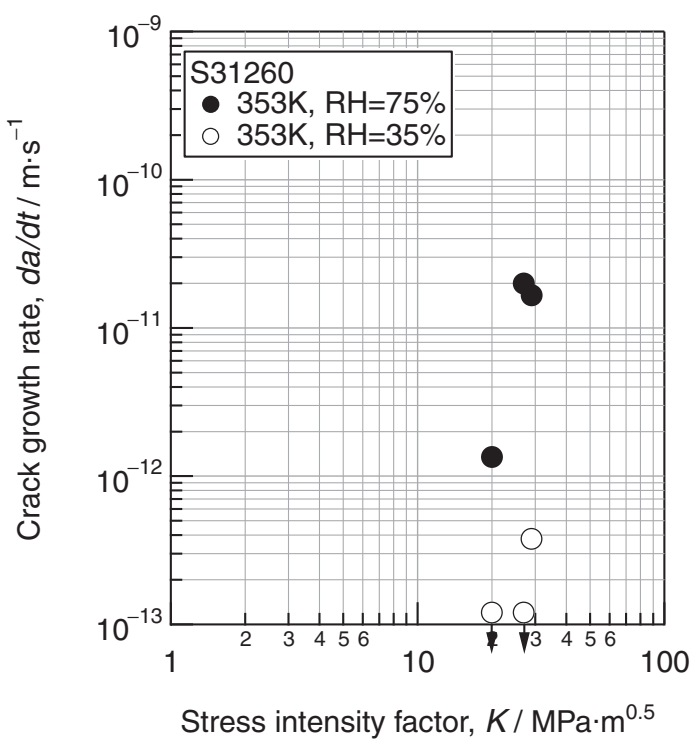

Fig. 12 Relationship between the crack growth rate and the stress intensity factor for S31260. 

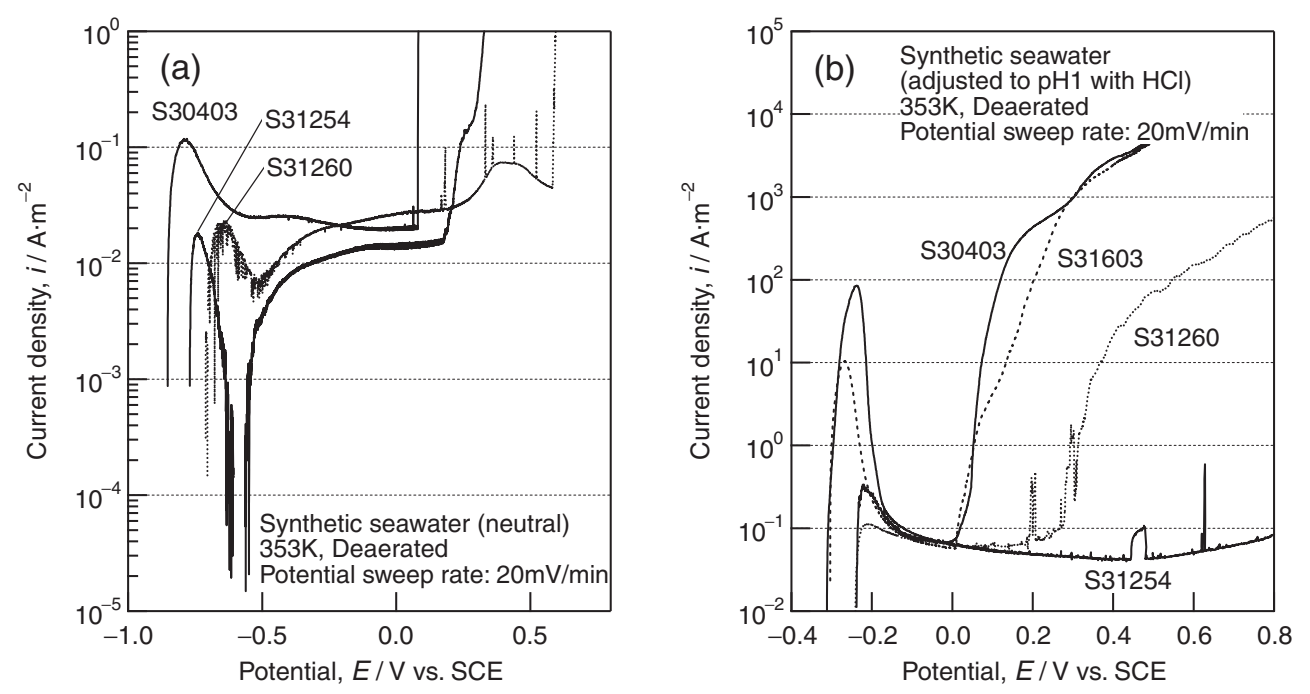

Fig. 13 Anodic polarization curves obtained in (a) neutral synthetic seawater, and (b) acidified synthetic seawater at $353 \mathrm{~K}$.

Table 2 Critical passivation current densities of stainless steel in neutral and acidified synthetic seawater.

\begin{tabular}{ccc}
\hline material & $\mathrm{pH} 1$ & neutral \\
\hline $\mathrm{S} 30403$ & 83.2 & 0.12 \\
$\mathrm{~S} 31603$ & 10.4 & no peak \\
$\mathrm{S} 31260$ & 0.11 & 0.024 \\
$\mathrm{~S} 31254$ & 0.34 & 0.012 \\
\hline & & $\left(\mathrm{A} \cdot \mathrm{m}^{-2}\right)$
\end{tabular}

why SCC hardly occurs for S31260 SS and S31254 SS at $323 \mathrm{~K}$. The probability of SCC initiation increases with temperature. This corresponds to the occurrence of cracks for S31260 SS and S31254 SS at $353 \mathrm{~K}$.

In this report, we evaluated the crack propagation rate. The crack growth rate of S31603 SS was $3 \times 10^{-10} \mathrm{~m} \cdot \mathrm{s}^{-1}$ at $353 \mathrm{~K}$ for $K=30 \mathrm{MPa} \cdot \mathrm{m}^{0.5}$ and that of $\mathrm{S} 31260 \mathrm{SS}$ was $4 \times$ $10^{-13} \mathrm{~m} \cdot \mathrm{s}^{-1}$ under the same test conditions. This means that the crack growth rate of S31603 SS was 750 times as large as that of S31260 SS. These results are consistent with the results of the constant-load test. To explain the results of crack growth rate measurement, an electrochemical evaluation was conducted. The mechanism of chloride-induced atmospheric SCC is assumed to be active-path SCC. The solution at the crack tip should be low $\mathrm{pH}$, so that the anodic dissolution rate in an acidic solution corresponds to the crack growth rate. The anodic current density of S31603 SS was 100 times as large as that of S31260 SS in synthetic seawater of $\mathrm{pH}$ 1. This result explains the difference in the crack growth rates.

\section{Conclusion}

(1) Candidate canister materials, S31260 SS and S31254 $\mathrm{SS}$, did not fail during $14800 \mathrm{~h}$ in the constant load test at $323 \mathrm{~K}$ with $\mathrm{RH}=35 \%$, whereas $\mathrm{S} 30403$ SS failed within $3000 \mathrm{~h}$. The same tendency also was obtained at $353 \mathrm{~K}$ with $\mathrm{RH}=35 \%$, where both the SSs did not fail during $37700 \mathrm{~h}$.

(2) The stress corrosion crack growth rate of S31260 SS was $4 \times 10^{-13} \mathrm{~m} \cdot \mathrm{s}^{-1}, 1 / 750$ of that for S31603 SS at $353 \mathrm{~K}$ with $\mathrm{RH}=35 \%$ under the stress intensity factor of $30 \mathrm{MPa} \cdot \mathrm{m}^{0.5}$.

(3) The anodic dissolution rate of S31260 SS was 1/100 of that for S31603 SS in synthetic sea water of $\mathrm{pH} 1$ at $353 \mathrm{~K}$.

(4) Atmospheric SCC induced by chloride hardly damages structures made of high-chromium and high-molybdenum stainless steels such as S31260 or S31254. Although small cracks occur on these materials, the crack propagation rate is sufficiently slow to sustain the SCC resistivity of the materials.

\section{REFERENCES}

1) M. Nakahara and K. Takahashi: Proc. JSCE Materials and Environments (Japan Society of Corrosion Engineering, Tokyo, 1985) pp. 217-220.

2) S. Shoji, N. Ohnaka, Y. Furutani and T. Saitoh: Boshoku-Gijutsu (presently Zairyo-to-Kankyo) 35 (1986) 559-565.

3) M. Mayuzumi, T. Arai and J. Tani: Proc. 13th APCCC (Osaka University, Japan, 2003).

4) M. Mayuzumi, T. Arai and K. Hide: Zairyou-to-Kankyou 52 (2003) 166-170.

5) M. Mayuzumi, H. Hayashibara, J. Tani and T. Arai: Zairyou-to-Kankyou 55 (2006) 20-24.

6) R. Kilian, U. Eberle, G. Brummer, H. Hoffmann, U. Ilg, V. Maier and M. Widera: 9th International Symposium on Environmental Degradation of Materials in Nuclear Power Systems (The Minerals, Metals \& Materials Society (TMS), 1999) pp. 347-357.

7) J. Hickling, P. L. Andresen R. M. Horn and H. Hoffmann: 9th International Symposium on Environmental Degradation of Materials in Nuclear Power Systems (The Minerals, Metals \& Materials Society (TMS), 1999) pp. 299-308.

8) H. Itoh, K. Ohnishi, M. Okunishi, K. Matsunaga and K. Murakami: Zairyou-to-Kankyou 54 (2005) 25-30.

9) M. Mayuzumi, J. Tani and T. Arai: submitted to Nucl. Eng. Design. 